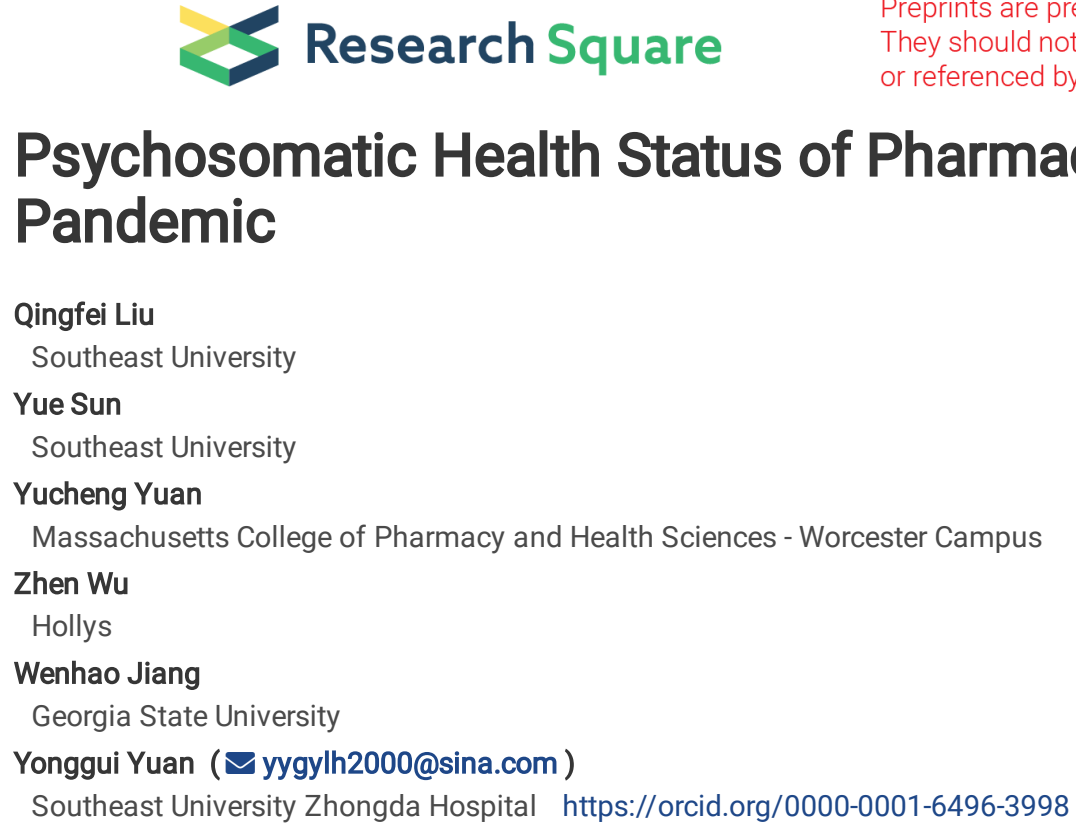

\title{
Psychosomatic Health Status of Pharmacy Staff During the COVID-19 Pandemic
}




\section{Abstract}

Background: Few studies have been conducted on psychosomatic health status of pharmacy staff during the COVID-19 pandemic. This study aims to investigate the incidence and influence factors of psychosomatic syndrome of pharmacy staff during the COVID-19 pandemic.

Methods: A total of 10721 pharmacy staff received online investigation through a period of 22 days from February $24^{\text {th }}$ to March $16^{\text {th }} 2019$. The investigation included the self-designed general situation questionnaire and Psychosomatic Symptoms Scale (PSSS), and 9118 participants provided valid questionnaire feedback. ANOVA was used to evaluate significant differences of psychosomatic syndromes in different subgroups. Multiple stepwise linear regression analysis was used to determine the main risk factors of psychosomatic syndrome.

Results: During the outbreak of COVID-19, the total incidence of psychosomatic syndrome was $21.7 \%$ in the pharmacy staff. The most common psychosomatic symptoms were sleep problems (dyscoimesis) and mood problems (irritability). Age was the most important risk factor of the observed psychosomatic syndromes and somatic symptoms, and education was identified affecting mostly psychological symptoms.

Conclusion: During the period of COVID-19, the psychosomatic problems of pharmacy staff were prominent. Age and educational background should be taken into account of potential intervention strategy. The relief of mood and sleep will aid the treatment effort.

\section{Plain English Summary}

The pandemic caused unbearable psychological stress to the people in China and all around the world. Faced with this public health emergencies, people were susceptible to psychosomatic syndrome. In order to investigate the incidence and influence factors of psychosomatic syndrome of pharmacy staff during the COVID-19 pandemic. A total of 10721 pharmacy staff received online investigation through a period of 22 days from February 24th to March 16th 2019. Results showed that the total incidence of psychosomatic syndrome was $21.7 \%$ in the pharmacy staff. The most common psychosomatic symptoms were sleep problems (dyscoimesis) and mood problems (irritability). Age was the most important risk factor of the observed psychosomatic syndromes and somatic symptoms, and education was identified affecting mostly psychological symptoms.

\section{Introduction}

The novel coronavirus pneumonia was highly contagious. The World Health Organization (WHO) has officially named 2019 novel coronavirus disease (COVID-19) ${ }^{[1]}$. The common symptoms included fever, fatigue, cough, shortness of breath, and other potential symptoms. Some scholars used the growth rate and other parameters to model the growth of the epidemic and found that the COVID-19 epidemic has great potential to cause a pandemic which has been proved ${ }^{[2]}$. The pandemic caused unbearable psychological stress to the people in China and all around the world. Faced with this public health emergencies, people were susceptible to psychosomatic syndrome. The mental health of medical worker was investigated in Wuhan, it was found that $29.9 \%$ of the medical staff who worked in the first-line had higher anxiety scores and obvious negative emotions during the COVID$19^{[3,4]}$. The levels of anxiety and depression were significantly higher during the outbreak period ${ }^{[5]}$. During the COVID-19, large flow of people was observed in the pharmacies. Higher risk of infection caused pharmacy staff to produce psychosomatic symptoms easily ${ }^{[6]}$. It is suggested that approximately $5 \%$ of people may develop post-traumatic stress disorder after a traumatic event ${ }^{[7]}$. Therefore, a better understanding of the physical and mental conditions of pharmacy staff and following positive psychological interventions are crucial to the pharmacy staff. However, the existing studies focused more on the people who have direct contact with pneumonia, and few studies were conducted on the mental health of pharmacy staff. This study aims to investigate the risk factors of psychosomatic symptoms of pharmacy staff by conducting a survey on their psychosomatic symptoms. We want to monitor and understand the psychosomatic symptoms of pharmacy staff in real time, in order to take appropriate psychological intervention measures.

\section{Methods}

\subsection{Research methods}

We conducted a questionnaire survey. A total of 10,721 questionnaires were collected, covering 31 provinces and regions. $96.5 \%$ of the people participated in the research through Wechat platform. The project lasted for 22 days from February 24th to March 16th .

This study was reviewed and approved by the Medical Ethical Committee of ZhongDa Hospital of Southeast University (approval number 2020ZDSYLL011-P01). All subjects signed informed consent before completing the questionnaire. (Some informed consent forms have been uploaded.)

\subsection{Data collection}

All information was obtained with a customized data collection form. The first part of the questionnaire was a general information questionnaire, including age, gender, educational background, marital status, and general health conditions. In the second part of the questionnaire, the psychosomatic symptoms scale (PSSS) was used to assess psychosomatic symptoms, including somatic factors (S) and psychological factors (P). There were 26 items in the scale, including 7 items for psychological factors (P) and 19 items for somatic factors (S). Four-level scoring was adopted 
in the scale. Participants were required to evaluate the frequency of their symptoms in last month. 0 points were scored for no symptoms, and 3 points were scored for most of the time. A total score $\geq 10$ suggested the high chance of existence psychosomatic disorders.

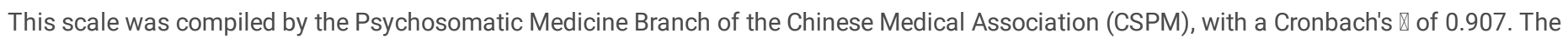
Cronbach's $₫$ values of the $P$ and $S$ subscales were 0.863 and 0.871 , respectively ${ }^{[8]}$.( Supplementary materials were provided ). All collected questionnaires were confidential, and no information linking participants' identifications and the questionnaires were saved.

\subsection{Statistical analysis}

Data analysis was done with IBM SPSS Statistics version 21.0. The score of PSSS scale was a continuous variable, which was expressed by mean and standard deviation. The socio-demographic data are categorical variables, were expressed as number and percentage (\%). The incidence rate of psychosomatic problem and the ratios of the PSSS items score more than 1 points were described by the frequency and ratio (\%). Firstly, in order to test whether there are differences in the incidence of PSSS among different groups of sociological variables, a one-way analysis of variance was performed. Secondly, multiple stepwise linear regression analysis was used to determine the main influencing factors of psychosomatic symptoms. Non-standardized regression coefficients were used to describe the contribution of the main influencing factors.

\section{Results}

\subsection{General demographic characteristics}

In this study, 10721 questionnaires were collected (the duplicate questionnaire was deleted, 9039 were valid and usable) and the effective rate was 84.3\%. The relevant information of socio-demographic variables (Age, Gender, Educational background, Marital status, and General health conditions) are shown in Table 1. Among the 9039 valid investigators, 1611 are males and 7428 are females. Education background was divided into four categories: primary, middle, undergraduate, and graduate.

Table 1

General demographic information

\begin{tabular}{|c|c|c|c|}
\hline Category & Group & Frequency & Percentage/\% \\
\hline \multirow[t]{5}{*}{ Age } & $18-25$ & 1637 & 18.11 \\
\hline & $26-30$ & 1814 & 20.01 \\
\hline & $31-40$ & 3300 & 36.51 \\
\hline & $41-50$ & 1922 & 21.26 \\
\hline & $\geqq 51$ & 366 & 4.10 \\
\hline \multirow[t]{2}{*}{ Gender } & male & 1611 & 17.82 \\
\hline & female & 7428 & 82.18 \\
\hline \multirow[t]{4}{*}{ Education } & primary & 85 & 0.94 \\
\hline & middle & 3661 & 40.50 \\
\hline & undergraduate & 5208 & 57.62 \\
\hline & graduate & 85 & 0.94 \\
\hline \multirow[t]{4}{*}{ Marital status } & single & 2225 & 24.62 \\
\hline & married & 6621 & 73.25 \\
\hline & divorced & 151 & 1.67 \\
\hline & widowhood & 42 & 0.46 \\
\hline \multirow[t]{4}{*}{ Health status } & healthy & 7948 & 87.94 \\
\hline & somatic & 706 & 7.81 \\
\hline & psychology & 10 & 0.11 \\
\hline & other & 374 & 4.14 \\
\hline
\end{tabular}

2.2 Differences incidence rates among subgroups of different populations 
The incidence of psychosomatic syndrome was $21.7 \%$ among all survey results (PSSS $\geq 10)$. (1)The incidence of psychosomatic syndrome was $20.53 \%$ for males and $21.96 \%$ for females. Compared with males, females more easily encountered psychology problems with high PSSS score(4.26 \pm 6.79 vs $4.64 \pm 6.52, P<0.05)$. (2) There were significant differences among different ages of the PSSS total and factor scores $(P<0.001)$. The higher incidence of psychosomatic symptoms were found in employees aged more than 51 years, with $61.06 \%$. The incidence of psychosomatic symptoms was $26.42 \%$ among aged $41-50$, and the people aged $31-40$ with psychosomatic symptoms was $23.00 \%$. The overall trend is the older you are, the more likely you are to have psychosomatic symptoms. (3)There were significant differences among different educational background of psychological factor $(P<0.05)$. The people with primary education background had the highest incidence rate of psychosomatic symptoms, the graduate group was lowest. The overall incidence of psychosomatic symptoms was similar as undergraduate group and middle group. (4) Marital status showed significant differences of the PSSS total and factor scores $(P<0.001)$, compared with the people who are married or single, widowed and divorced more easily encountered psychology problems with high PSSS score $(P<0.05)$. (5) There showed no significant difference in general health conditions. However, the incidences of PSSS in people with psychosomatic diseases or mental disorders were relatively higher. Are shown in Table 2.

Table 2

Differences incidence rates among subtypes of different populations

\begin{tabular}{|c|c|c|c|c|c|c|c|c|c|c|c|c|c|c|}
\hline \multirow[t]{2}{*}{ Group } & & \multicolumn{4}{|l|}{ Total } & \multicolumn{4}{|c|}{ Somatic } & \multicolumn{4}{|c|}{ Psychology } & \multirow[t]{2}{*}{ incidence } \\
\hline & & $M$ & $S D$ & $F$ & $P$ & $M$ & $S D$ & $F$ & $P$ & $M$ & $S D$ & $F$ & $P$ & \\
\hline Total & & 6.26 & 8.90 & & & 1.70 & 2.67 & & & 4.57 & 6.57 & & & 21.7 \\
\hline Age & & & & 26.63 & $\begin{array}{l}< \\
0.001\end{array}$ & & & 5.84 & $\begin{array}{l}< \\
0.001\end{array}$ & & & 37.26 & $\begin{array}{l}< \\
0.001\end{array}$ & \\
\hline & $18-25$ & 5.20 & 8.87 & & & 1.570 & 2.79 & & & 3.63 & 6.40 & & & 23.43 \\
\hline & $26-30$ & 5.13 & 7.83 & & & 1.50 & 2.50 & & & 3.63 & 5.63 & & & 17.08 \\
\hline & $31-40$ & 6.56 & 8.74 & & & 1.80 & 2.65 & & & 4.76 & 6.43 & & & 23.00 \\
\hline & $41-50$ & 7.46 & 9.78 & & & 1.82 & 2.74 & & & 5.64 & 7.37 & & & 26.42 \\
\hline & $\geqq 51$ & 7.97 & 9.45 & & & 1.83 & 2.67 & & & 6.14 & 4.73 & & & 61.06 \\
\hline Gender & & & & 3.52 & 0.06 & & & 0.62 & 0.43 & & & 4.95 & 0.03 & \\
\hline & male & 5.89 & 9.29 & & & 1.65 & 2.80 & & & 4.24 & 6.79 & & & 20.53 \\
\hline & female & 6.35 & 8.82 & & & 1.71 & 2.64 & & & 4.64 & 6.52 & & & 21.96 \\
\hline Education & & & & 1.07 & 0.36 & & & 7.33 & $<.001$ & & & 0.98 & 0.40 & \\
\hline & primary & 6.84 & 7.60 & & & 1.44 & 2.10 & & & 5.41 & 6.33 & & & 28.13 \\
\hline & middle & 6.12 & 8.38 & & & 1.55 & 2.44 & & & 4.57 & 6.27 & & & 21.43 \\
\hline & undergraduate & 6.34 & 9.17 & & & 1.80 & 2.80 & & & 4.53 & 6.69 & & & 21.95 \\
\hline & postgraduate & 7.45 & 14.41 & & & 2.10 & 4.10 & & & 5.35 & 10.46 & & & 20.93 \\
\hline $\begin{array}{l}\text { Marital } \\
\text { status }\end{array}$ & & & & 22.58 & $\begin{array}{l}< \\
0.001\end{array}$ & & & 6.40 & $\begin{array}{l}< \\
0.001\end{array}$ & & & 30.10 & $\begin{array}{l}<.001 \\
0.00\end{array}$ & \\
\hline & single & 5.17 & 8.58 & & & 1.57 & 2.75 & & & 3.60 & 6.16 & & & 16.89 \\
\hline & married & 6.56 & 8.89 & & & 1.73 & 2.62 & & & 4.83 & 6.60 & & & 23.17 \\
\hline & divorced & 8.05 & 9.93 & & & 1.99 & 2.80 & & & 6.05 & 7.64 & & & 29.14 \\
\hline & widowhood & 12.31 & 15.32 & & & 3.10 & 4.53 & & & 9.21 & 11.09 & & & 40.48 \\
\hline $\begin{array}{l}\text { Health } \\
\text { status }\end{array}$ & & & & 1.45 & 0.121 & & & 0.91 & 0.548 & & & 1.62 & 0.066 & \\
\hline & healthy & 6.20 & 8.88 & & & 1.69 & 2.67 & & & 4.51 & 6.54 & & & 21.38 \\
\hline & somatic & 8.18 & 10.00 & & & 2.14 & 2.95 & & & 6.04 & 7.39 & & & 25.54 \\
\hline & psychology & 5.25 & 7.20 & & & 1.26 & 1.94 & & & 3.98 & 5.51 & & & 23.08 \\
\hline & other & 6.61 & 9.80 & & & 1.79 & 2.83 & & & 4.82 & 7.29 & & & 21.69 \\
\hline
\end{tabular}




\subsection{The incidence of different psychosomatic symptoms}

The number of PSSS score above 1 point was described by frequency and proportion (\%). According to the PSSS score, The most common somatic symptom was dyscoimesis (item 26 ) with $32.47 \%$. The most common mood symptom was easier lose his temper and irritability than usual (item 11 ) with $31.40 \%$. See Fig. 1.

\subsection{Multiple linear regression}

The results of multiple linear regression showed that age was the most important risk factor of the observed psychosomatic symptoms $(B=0.682, P<$ $0.001)$ and somatic symptoms $(B=0.574, P<0.001)$. The education affected mostly psychological symptoms $(B=0.298, P<0.001)$. See Table 3 .

Table 3

PSSS total scores multiple linear regression analysis

\begin{tabular}{|c|c|c|c|c|c|}
\hline Model & Factors & Beta & Standard error & $t$ & $P$ \\
\hline \multirow[t]{3}{*}{1} & Age & 0.687 & 0.105 & 6.523 & 0.000 \\
\hline & Marital & 0.585 & 0.245 & 3.010 & 0.017 \\
\hline & Education & 0.533 & 0.177 & 2.386 & 0.003 \\
\hline \multirow[t]{2}{*}{2} & Education & 0.293 & 0.053 & 5.491 & 0.000 \\
\hline & Age & 0.123 & 0.025 & 4.926 & 0.000 \\
\hline \multirow[t]{2}{*}{3} & Age & 0.574 & 0.077 & 7.478 & 0.000 \\
\hline & Marital & 0.472 & 0.180 & 2.615 & 0.009 \\
\hline
\end{tabular}

Note: model 1 refers to the total score of PSSS as the dependent variable, model 2 based on psychological factors, model 3 based on somatic factors. The independent variables are consistent among the three models, including general demographic data such as age, gender and education background.

\section{Discussion}

The overall incidence of psychosomatic syndrome among pharmacy staff was $21.7 \%$ during the COVID-19. The outbreak of COVID-19 was a serious public health event. Normally, people were encountered with huge psychological pressure during a serious public health event. Pharmacy staff faced great occupational risks and customer anxiety, they were more likely to be fearful, anxious, irritable, and sensitive ${ }^{[9]}$. The present results suggested that more than $1 / 5$ pharmacy staff showed psychosomatic symptoms. The incidence of anxiety was $20.2 \%$ according to an investigation into the general public during the epidemic ${ }^{[10]}$. People who engaged in work related to epidemic had significantly worse mental health condition than the general population during the COVID-19 epidemic ${ }^{[11]}$.

This study also found that subjects with the characters of females, aged, lower education background, widowed and divorced, and history of somatic and psychological disease had a higher rate of psychosomatic syndromes. Female showed higher incidence of psychosomatic symptoms than the male, it might lie in women were more susceptible to stress ${ }^{[12]}$. In a survey on individuals' psychosomatic state caused by overtime work, psychological syndromes were found, the health risk of women caused by overtime work was higher than men. Some researchers investigated the mental health of front-line medical staff and found that the anxiety rate of female medical workers was higher than men ${ }^{[13]}$. By investigating the anxiety and depression of the elderly during the epidemic period and found that the anxiety and depression of women was much higher than men [14].

Age was also a crucial factor, our study showed that age was the most important risk factor of the observed psychosomatic syndrome and somatic symptoms. The older individuals adapted to the gradual weakening of social supports with more difficulties, coupled with the decline of physical functions ${ }^{[15]}$. Older people were more likely to produce psychosomatic symptoms in many extreme situations. This research result was consistent with the development trend of individual ${ }^{[16]}$. Another study showed that $37.1 \%$ of the elderly experienced emotional reactions during the epidemic period $^{[14]}$.

Education affected psychosomatic symptoms. The incidence of psychosomatic symptoms was the lowest in the postgraduate group and the highest was primary group. Pu et al. ${ }^{[17]}$ showed that in the overall health model, people with higher education were more inclined to have a healthier lifestyle. They were relatively calm when an acute stress event occurred and less likely to have psychosomatic symptoms. Our results also showed that education background played an important role in psychological factors. Stewart-Brown et al. ${ }^{[18]}$ found that the prevalence of mental health problems was the highest among the less educated population, and better education might improve mental health through better labor market outcomes and health inputs (such as more physical activity, earlier detection, and better access to psychotherapy).

Widowed and divorced people might take more pressure, such as economic pressure and social pressure. A research found that good marital status could significantly increase happiness, allowing people to face adversity, then promote the individual's physical and mental health ${ }^{[19]}$. Divorced and 
widowed individuals had more psychosomatic symptoms during the epidemic period ${ }^{[20]}$. For those who lack a warm family environment were susceptible to negative environment and had difficulty in adapting to changes, so they were more likely to develop psychosomatic symptoms ${ }^{\text {[21] }}$.

In the present study, the most common psychosomatic symptoms were sleep problems (dyscoimesis) and mood problems (irritability). Mood and sleep problems affect each other mutually. Poor sleep leads to negative mood, and it in turn affected sleep quality. Some researchers investigated the psychological health of the public during the epidemic, and found that the most common psychosomatic symptoms respectively were fatigue and unhappiness ${ }^{[22]}$. Under the pressure of the COVID-19, sleep difficulties, lack of interest, and avoidance of anxiety were the most common symptoms of ordinary people according the research of Yue et al. ${ }^{[23]}$. During the outbreak of Ebola virus in 2014, Mohammed et al. ${ }^{[24]}$ investigated that one of the most common symptoms of survivors was lack of sleep. Du et al. ${ }^{[25]}$ found that poor sleep quality was related to the aggravation of depression and anxiety symptoms among medical personals in hospitals in Wuhan. Sang et al. investigated the emotions of medical staff during the outbreak of Middle East respiratory syndrome coronavirus in South Korea, and found that many medical staff experienced severe emotional stress, mainly including traumatic stress, anxiety and depressive symptoms ${ }^{[26]}$. During the COVID-19, the overall prevalence of dyscoimesis was $18.2 \%$ among the Chinese public ${ }^{[27]}$. Early negative emotions such as fatigue and irritability might be caused by high-intensity work and lack of sleep ${ }^{[28]}$. Taken together, we should emphasize the importance of assessment and management of existing persistent sleep and mood symptoms for the pharmacy staff even after the acute period.

Severe psychosomatic symptoms caused by a traumatic event were difficult to mitigate automatically ${ }^{[29,30]}$. Psychological counseling was particularly important for pharmacy staff. Understanding the psychosomatic symptoms could help pharmacy staff better response to a catastrophic public health emergency. The present research provided a good perspective. The psychotherapy should be considered for the common symptoms of mood and sleep. Due to the high contagious risk, it was difficult to interview face to face, so the remote written counseling might become a new psychological counseling model in this situation ${ }^{[31,32]}$. Online psychological counseling may be a viable option

However, there were some limitations on this study. Firstly, this was a cross-sectional study with a significant difference in sample size in different subgroups. It may undermine the results of the study. Most of the subjects are self-tested through Wechat platform, so it was difficult to ensure the balance of the samples at all levels. Secondly, when we investigated the influencing factors of psychosomatic syndromes among pharmacy staff, normal demographic variables were taken into account. In fact, the influencing factors may include personality characteristics and environmental factors. Finally, the research method was unitary, we only used quantitative studies and few qualitative considerations.

\section{Conclusion}

During the COVID-19 pandemic, pharmacy staff tended to show psychosomatic symptoms due to working circumstances. Psychological workers should pay more attention to this group, while their age and education should be taken into account during potential intervention. The prognosis will be better if we focus on mood and sleep.

\section{List Of Abbreviations}

COVID-19 Coronavirus Disease 2019

PSSS Psychosomatic Symptoms Scale

WHO World Health Organization

\section{Declarations}

\section{Author contributors}

YYG designed the study. SY collected the data. SY and LQF analyzed data. LQF wrote the manuscript. YC, WZ, JWH,YYG and YYY revised the report.

\section{Role of the funding source}

The funder of the study had no role in data collection, data analysis, data interpretation, or writing of the report. The corresponding author was responsible for the full part of this work and had decision to submit for publication.

\section{Conflict of interest statement}

We declare no competing interests.

\section{Acknowledgments}

This work was supported by the Medical Innovation Teams of Jiangsu province (CXTDB2017005, YYG). The authors appreciate all participants all the participants who participated in the survey. All presentations of case reports have been agreed for publication. 
The raw/processed data required to reproduce these findings cannot be shared at this time as the data also forms part of an ongoing study.

\section{Ethics Approval}

This study was reviewed and approved by the Medical Ethical Committee of ZhongDa Hospital of Southeast University (approval number 2020ZDSYLL011-P01). All subjects signed informed consent before completing the questionnaire.(Some informed consent forms have been uploaded.).

\section{References}

1. COVID-19 prevention and control expert group of Chinese preventive medical association. Current understanding of the epidemiology of COVID19. Chinese Journal of Epidemiology. 2020, 41:139-144. (Article in Chinese)

2. Jung SM, Akhmetzhanov AR, Hayashi K, et al. Real-Time Estimation of the Risk of Death from Novel Coronavirus (COVID-19) Infection: Inference Using Exported Cases. J Clin Med. 2020,9(2):523.

3. Zhang Y, Zhang XJ, Peng JX, Fang P. A survey on the mental health of Wuhan medical staff fighting COVID-19. Journal of Tropical Medicine.2020,04:1-7. (Article in Chinese)

4. Dang S, Li GL, Huang JT, Li QM, Peng B, Yao WX. Investigation on the physical and mental experience of medical personnel fighting COVID-19. Anhui Medicine.2020,24(03):500-504. (Article in Chinese)

5. Xu J, Xu QH, Wang CM, Wang J. Psychological status of surgical staff during the COVID-19 outbreak. Psychiatry Res. 2020(11), 288:112955.

6. Wang JW, Guan Y, Cao SS, et al. Novel coronavirus infection: expert consensus on prevention and control strategies for retail pharmacies. Chinese Pharmaceutical Journal. 2020,55(04):278-283. (Article in Chinese)

7. Ursano RJ, Zhang L, Li H, et al. PTSD and traumatic stress from gene to community and bench to bedside. Brain Res. 2009, $1293: 2-12$.

8. Li L, Peng TC, Liu R, et al. Development of the psychosomatic symptom scale (PSSS) and assessment of its reliability and validity in general hospital patients in China. Gen Hosp Psychiatry.2020, 64:1-8.

9. Mohamed EEZ, Josef DJ. From SARS to COVID-19: A previously unknown SARS-related coronavirus (SARS-CoV-2) of pandemic potential infecting humans-Call for a One Health approach. One Health. 2020,9:100-124.

10. Liu QF, Yuan YG. The influence of neurotic personality traits on anxiety of people during COVID-19 epidemic prevention. Advances in Psychology.2020,3(10):359-366. (Article in Chinese)

11. Wang YY, Jia XR, Song JQ, et al. Investigation and analysis of the mental health status of medical staff during the COVID-19 epidemic. Journal of Wuhan University (medical). 2020:1-5. (Article in Chinese)

12. Li YQ, Zhang S. "Workplace constraints" -- the health effects of overtime work on employees and gender differences. Population and Economy. 2020,01:16-28. (Article in Chinese)

13. Huang JZ, Han MF, Luo TD, Ren AK, Zhou XP. Mental health survey of 230 medical staff in a tertiary infectious disease hospital for COVID-19. Zhonghua Lao Dong Wei Sheng Zhi Ye Bing Za Zhi. 2020, 38(3):192-195.

14. Meng H, Xu Y, Dai JL, et al. The Psychological effect of COVID-19 on the Elderly in China. Psychiatry Res . 2020, $289: 112983$.

15. Wettstein M, Spuling SM, Cengia A. Trajectories of functional health and its associations with information processing speed and subjective wellbeing: The role of age versus time to death. Psychol Aging. 2020, 35(2):190-203.

16. Zhai B. The enlightenment of Erickson's theory of psychological development stages to the subjective educators. JiuCheng Education. 2019,01:29-31. (Article in Chinese)

17. Pu X. A study on the influence of socioeconomic status on health- empirical research based on CFPS2014.East China Normal University. 2017, 2:1-61. (Article in Chinese)

18. Stewart-Brown S, Samaraweera PC, Taggart F, et al. Socioeconomic gradients and mental health: implications for public health. Br J Psychiatr. 2015,206 (6):461-465

19. Cheng SY. Whether marriage can promote health. East China normal university-- Empirical analysis based on the Comprehensive Survey of Chinese Society in 2013 and 2015. East China Normal University. 2019,09:1-59. (Article in Chinese)

20. Tian F, Li H, Tian S, et al. Psychological symptoms of ordinary Chinese citizens based on SCL-90 during the level I emergency response to COVID19. Psychiatry Res.2020,288:2-9.

21. Norman A, Børge S, Kari JL, Kirsti M. Life satisfaction and mental health among transgender students in Norway. BMC Public Health. 2020,20 (1):138.

22. Ge CH, Zhao TT, Ma MD, et al. A survey of public mental health during the COVID-19 outbreak. Journal of Bengbu Medical College.2020,45(02):159-162. (Article in Chinese)

23. Yue YY , Li L, Liu R, et al. Psychosomatic problems of the population during the outbreak of the COVID-19 in China. Psychosom Med. 
24. Mohammed A, Sheikh TL, Gidado S, et al. An evaluation of psychological distress and social support of survivors and contacts of Ebola virus disease infection and their relatives in Lagos, Nigeria: a cross sectional study-2014. BMC Public Health. 2015,15:824.

25. Du J, Dong L, Wang T, et al. Psychological symptoms among frontline healthcare staff during COVID-19 outbreak in Wuhan.Gen Hosp Psychiatry. 2020,4:31.

26. Sang ML, Won SK, Ah-Rang C, et al. Psychological impact of the 2015 MERS outbreak on hospital staff and quarantined hemodialysis patients. Comprehensive Psychiatry.2018, 87:123-127.

27. Huang Y, Zhao N. Generalized anxiety disorder, depressive symptoms and sleep quality during COVID-19 outbreak in China: a web-based crosssectional survey. Psychiatry Res. 2020, 288:112954.

28. Niuniu SM, Luoqun WM, Suling SB, et al. A qualitative study on the psychological experience of caregivers of COVID-19 patients. Am J Infect Control.2020, 48(6):592-598.

29. Montemurro N. The emotional impact of COVID-19: From medical staff to common people. Brain Behav Immun. 2020, 87:23-24.

30. Ahmed MZ, Ahmed O, Aibao Z, et al. Epidemic of COVID-19 in China and associated Psychological Problems. Asian J Psychiatr. $2020 \otimes 51: 102092$.

31. Duan L, Zhu G. Psychological interventions for people affected by the COVID-19 epidemic. Lancet Psychiatry. 2020, 7(4):300-302.

32. Xiao CF. A Novel Approach of Consultation on 2019 Novel Coronavirus (COVID-19)-Related Psychological and Mental Problems: Structured Letter Therapy. Psychiatry Investig. 2020, 17(2):175-176.

\section{Figures}

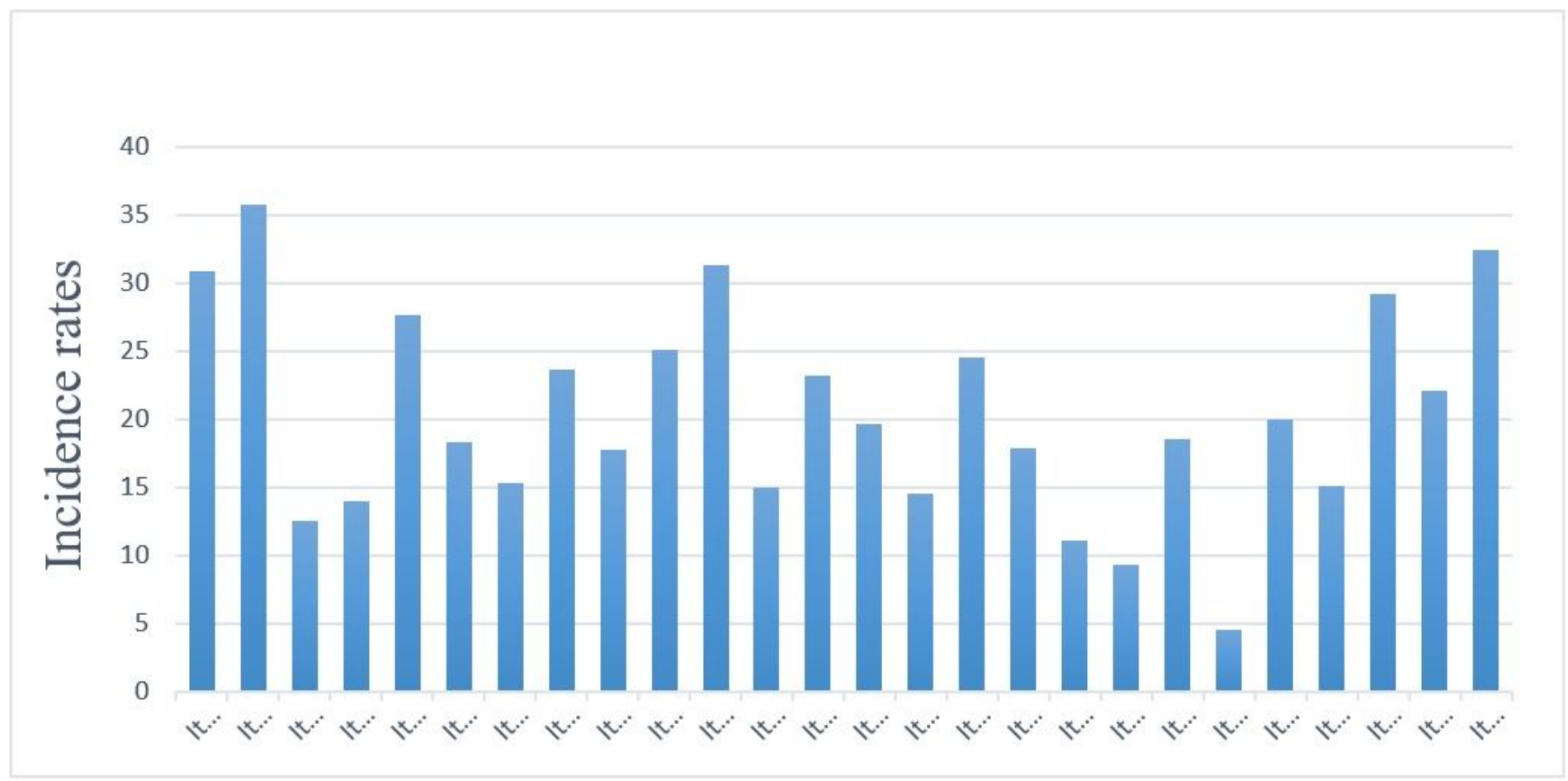

Figure 1

Incidence rates of all items of PSSS. Note: Specific items are described in the appendix. 